\title{
Maternal genetic correlations in the seed rain: effects of frugivore activity in heterogeneous landscapes
}

\author{
Cristina García ${ }^{1}$, Pedro Jordano ${ }^{2 *}$, Juan Miguel Arroyo ${ }^{2,3}$ and José Antonio Godoy ${ }^{2}$ \\ ${ }^{1}$ Department of Plant Biology, College of Arts and Sciences, University of Georgia, 125 Plant Miller Sciences, Athens, \\ GA 30602, USA; ${ }^{2}$ Integrative Ecology Group (IEG), Estación Biológica de Doñana, CSIC, c/Americo Vespucio s/n, \\ Isla de La Cartuja, 41092 Sevilla, Spain; and ${ }^{3}$ Laboratorio de Ecología Molecular (LEM), Estación Biológica de \\ Doñana, CSIC, c/Americo Vespucio s/n, 41092 Sevilla, Spain
}

\section{Summary}

1. A frugivore-generated seed rain combines dispersed propagules from source trees located all over the landscape. By selecting deposition sites, frugivorous vertebrates set the maternal genetic correlations in the seed rain, i.e. how maternal progenies become distributed over the landscape relative to the source trees and other conspecifics. This aspect, however, remains virtually unexplored despite its central effect on the demographic and genetic structure in plant populations.

2. We examined three components of maternal genetic correlations in the seed rain: the number of distinct contributing maternal trees (maternal richness), the genetic relatedness among contributing trees (maternal relatedness) and the probability that two seeds drawn from the same seed trap come from the same maternal tree (correlated maternity).

3. We studied the maternal genetic correlations in a vertebrate-generated seed rain of a Prunus mahaleb population located in a heterogeneous landscape (c. 25 ha). Based on the multilocus genotypes provided by microsatellite markers, we identified the source tree of dispersed seeds sampled in seed traps and distributed among six microhabitat types.

4. Seed traps showed a spatial aggregation of maternally related seeds that varied among microhabitats in relation to the frugivore foraging preferences, resulting in variable maternal correlations across the landscape. We found: (i) seed traps with high maternal richness and low genetic relatedness in sites dominated by high shrubs, frequently visited by most frugivore species; (ii) seed traps with low maternal richness, high relatedness and increased correlated maternity values resulting from recurrent dispersal from few isolated source trees to sites dominated by non-fleshy fruited species; and (iii) seed traps under pine trees with high maternal richness and relatedness (but low correlated maternity) due to long-distance dispersal events from several source trees growing closely to each other.

5. Synthesis. Maternal progenies became distributed non-randomly over the landscape, where trees with similar maternal neighbourhoods tended to disperse their progeny to similar microhabitats. This resulted in genetic limitation, i.e. the failure of maternal trees to reach all microhabitats, as well as the failure of the microhabitats to cast all maternal progenies. Both the genetic limitation and the spatial aggregation of maternal progenies, driven by frugivore activity, might pervasively determine recruitment and spatial genetic patterns in heterogeneous populations.

Key-words: correlated maternity, genetic limitation, heterogeneous landscape, maternal progenies, maternal richness, microhabitat, Prunus mahaleb, seed dispersal by vertebrates, seed rain, seed trap

\section{Introduction}

The outcomes of plant-animal mutualisms involving seed dispersal directly influence plant population recruitment patterns (Nathan \& Muller-Landau 2000), their genetic structure

*Correspondence author. E-mail: jordano@ebd.csic.es
(Hamrick, Murawski \& Nason 1993), and their spatial dynamics within and among populations (Hubbell 2001; Levin et al. 2003). The frugivorous vertebrates generate seed rain patterns that capture the foraging and post-feeding movements of these animals; sites chosen for roosting, resting, perching or displaying frequently receive a disproportionate number of seeds generating spatially clumped seed rain patterns (Howe \& 
Smallwood 1982; Schupp, Milleron \& Russo 2002). The spatial distribution of the maternal progenies in the seed rain is reported to determine the recruitment patterns (Augspurger \& Kitajima 1992; Donohue 2003). Seed clumps with mixed maternal seed sources showed increased seedling survival compared with genetically homogeneous seed clumps in certain microhabitats (i.e. a context-dependent response). Furthermore, kin-structured dispersal observed in multi-seeded fruits dispersed by frugivores results in strong patterns of genetic structure even in the presence of long-distance dispersal (Torimaru et al. 2007). In spite of having pervasive effects in determining plant population recruitment, the embedded genetic patterns arising from frugivore activity in heterogeneous landscapes remain virtually unknown.

Frugivore activity results in recruitment limitation when dispersed seeds fail to reach distant sites (distance limitation), when they are distributed among a few available sites (spatial limitation) or when seeds are selectively dispersed from few fruiting trees (source-biased dispersal) (Jordano \& Godoy 2002; Schupp, Milleron \& Russo 2002). In vertebratedispersed species inhabiting heterogeneous landscapes, these three types of seed dispersal limitation are likely to occur simultaneously. Furthermore, frequent visits of frugivorous vertebrates from certain fruiting trees to selected deposition sites result in a high number of correlated dispersal events, i.e. seeds are dispersed from the same maternal tree to the same deposition site (Epperson \& Álvarez-Buylla 1997). This is the case for numerous frugivorous birds and mammals that frequently revisit certain sites for displaying (Wenny \& Levey 1998), roosting (Jordano \& Schupp 2000) or resting (Russo \& Augspurger 2004). These foraging patterns likely result in a highly source-biased and/or spatially aggregated dispersal where we can expect an uneven contribution of the source trees to the seed rain and a highly non-random distribution of their progeny among microhabitat types (Hampe et al. 2008). These two key aspects of the seed rain, i.e. the identity of the contributing trees and the distribution of their maternal progenies after dispersal by frugivorous vertebrates in an environmentally structured landscape remain unexplored in spite of their potential influence in determining plant recruitment patterns.

In this study, we applied a direct maternal assignment method to describe how different maternal trees distribute their seed progeny among different microhabitat types in Prunus mahaleb, a fleshy-fruited species dispersed by frugivorous birds and mammals. The study site was located in a mosaic-like landscape with physiognomically distinct vegetation patches and soil types (hereafter microhabitats). Most frugivore species showed a strong preference for covered microhabitats and avoided open ones (without woody plant cover) (Jordano \& Schupp 2000; García-Castaño 2001). Previous work has documented the foraging patterns of a diverse assemblage of frugivorous birds with a prevalent role as seed dispersers for Phoenicurus ochruros, Turdus viscivorus, Erithacus rubecula and Sylvia communis and of carnivorous mammals (Jordano \& Schupp 2000; Jordano et al. 2007). These studies showed that the effectiveness of seed dispersal by frugivorous vertebrates varied widely among fruiting trees (source-biased dispersal) and that the number of dispersed seeds per deposition site strongly depended on microhabitat and spatial location (spatially aggregated dispersal, see Jordano \& Schupp 2000; García-Castaño 2001; Jordano et al. 2007).

Given the seed rain that frugivorous vertebrates generate, we ask how different source trees contribute seeds to specific microhabitat types in the population and how genetically related the seeds dispersed to the same deposition site are. By genotyping the endocarp of dispersed seeds (a tissue of maternal origin), we specifically pursue to identify the source tree of dispersed seeds in the population (Godoy \& Jordano 2001) and to estimate the maternal genetic correlations set in the seed rain following a similar approach as in Grivet, Smouse \& Sork (2005). Maternal genetic correlations were assessed as: (i) the number of distinct contributing trees to different microhabitats (hereafter maternal richness); (ii) the relatedness among trees contributing seeds to one deposition site (maternal relatedness); and (iii) the probability that two seeds drawn at random from the same seed trap come from the same mother tree (hereafter correlated maternity).

By using a thorough sample of a vertebrate-dispersed seed rain that has been spread all over the population and a maternity analysis that allows to identify the source tree of dispersed seeds (Godoy \& Jordano 2001; Ziegenhagen et al. 2003; Grivet, Smouse \& Sork 2005; Jones et al. 2005), we aim to: (i) identify the source trees contributing to the seed rain; (ii) describe how maternal trees distribute their progeny among microhabitats; (iii) characterize the maternal genetic correlations in the seed rain; and (iv) assess the role of landscape features linked to the location of the seed traps in shaping the maternal genetic correlation patterns in the seed rain. We finally interpret our results considering previous information on the feeding and post-feeding movement patterns of frugivores to depict a comprehensive picture of the role of frugivores in determining the spatial genetic features in the seed rain.

\section{Materials and methods}

\section{SPECIES AND STUDY SITE CHARACTERISTICS}

Prunus mahaleb (L.) (Rosaceae), a fleshy-fruited tree dispersed by frugivore vertebrates (Jordano \& Schupp 2000; García-Castaño 2001; Jordano et al. 2007), is frequently visited during July to midAugust by small- and medium-sized birds and carnivorous mammals (García-Castaño 2001; Jordano et al. 2007). Our study site is located at $1615 \mathrm{~m}$ a.s.l. in Nava de las Correhuelas, (Parque Natural de las Sierras de Cazorla, Segura y las Villas, Jaén province, Spain, 3759' $\mathrm{N}, 2^{\circ} 54^{\prime} \mathrm{W}$ ). At this site, 196 adult trees are distributed over an area of 25 ha in clusters of variable density (see García, Jordano \& Godoy 2007). Six physiognomically different microhabitats are combined in a mosaic-like landscape (see below).

\section{SEED RAIN SAMPLING DESIGN}

Seed rain was sampled using seed traps distributed according to a random stratified design by microhabitat type. We arranged 614 
sampling points, each consisting of two seed traps (for further details see García-Castaño 2001). The seed traps consisted of $0.16-\mathrm{m}^{2}$ large aluminium trays each attached to the soil with a nail and covered with an $8-\mathrm{mm}$ mesh wire to prevent seed predation by rodents. We recorded the $x, y$ coordinates for each sampling point and assigned the sampling point to one of six different microhabitats $(\mathrm{MH})$ defined according to the type of plant cover above it (see Jordano \& Schupp 2000). Three microhabitats corresponded to fleshy-fruited species: (i) MH-Prunus, dominated by adult P. mahaleb trees; (ii) MH-High shrub, dominated by fleshy-fruited, high shrubs, with woody cover reaching over $1.5 \mathrm{~m}$ height (Crataegus monogyna, Lonicera arborea, Rosa spp.); and (iii) MH-Low shrub, dominated by low (below $1.5 \mathrm{~m}$ height) shrub species such as Juniperus communis, Berberis hispanica and J. sabina. Three other microhabitats were dominated by nonfleshy fruited species: (i) MH-Pinus, dominated by pine trees (Pinus nigra, subsp. salzmannii); (ii) MH-Acer-Quercus dominated by Acer granatensis and Quercus faginea or Q. ilex, which were scattered in the population; and (iii) MH-Open, which included rocky soil and grassland. We set at least 100 sampling points per microhabitat type with a randomized spatial location within each microhabitat (Fig. S1 in Supporting Information).

\section{MATERNAL NEIGHBOURHOOD CHARACTERISTICS}

Besides identifying the microhabitat type for each sampling point, we also recorded the physiognomic characteristics at the growing site for each maternal tree (i.e. hereafter the maternal neighbourhood) as well as the tree characteristics. The maternal phenotype was described by basal stem diameter and the area occupied by the canopy (CNPY) The spatial and physiognomic variation of the maternal neighbourhoods was described by a set of eight variables measured under the canopy of the adult tree at four cardinal points and within a $30-\mathrm{m}$ radius from the adult tree (based on Jordano \& Schupp 2000). These variables included: (i) mean number of woody species under canopy (UCSP); (ii) mean height of the woody vegetation under the canopy (UCHGT); (iii) mean percentage of woody vegetation coverage under the canopy (UCCOVA); (iv) mean percentage of rocky soil coverage under the canopy (UCCOVR); (v) mean number of woody species outside canopy (OCSP); (vi) mean height of the woody vegetation outside the canopy (OCHGT); (vii) mean percentage of woody vegetation coverage outside the canopy (OCCOVA); and (viii) mean percentage of rocky soil coverage outside the canopy (OCCOVR). Additionally, we measured the distance from each tree to the nearest rocky outcrop (DROCK) and to the pine forest edge (DFOREST). Finally, we estimated the degree of clumping of the fruiting trees by estimating the area of the Dirichlet tile associated with each adult tree (DIR.AREA). By definition, a Dirichlet tile or tesselation contains all points that are closer to a given reference point (maternal tree) than to any other reference point in the population (Legendre \& Legendre 1998). The borders defining each tile contain all points equidistant from two reference points (maternal trees). Thus, isolated trees will present large tile areas whereas clumped trees will yield small tile areas. The computation of the Dirichlet tile areas was performed with R (library spatial) (R Development Core Team 2009).

\section{MOLECULAR METHODS AND MICROSATELLITE GENOTYPING}

All adult trees were previously genotyped with 11 polymorphic microsatellite markers (Godoy \& Jordano 2001; García et al. 2005). We genotyped the endocarp of all dispersed seeds collected in all microhabitats and of a random subsample of seeds from MH-Prunus and MH-High shrub (Table 1) due to the high number of seeds deposited in these microhabitats. We used nine microsatellite markers to identify the source tree of the dispersed seeds (Godoy \& Jordano 2001). We excluded two microsatellite markers from the initial set of 11 due to the low variability of one of them and a high rate of amplification failure from endocarp DNA of the other one. Briefly, endocarps were split open, separated from the embryonic tissue and immersed in liquid nitrogen before being ground in a bench-top laboratory mixer mill (Retsch MM200; Retsch GmbH, Haan, Germany). DNA was extracted following Cheung, Hubert \& Landry (1993), resuspended in $100 \mu \mathrm{L}$ of TLE $(10 \mathrm{mM}$ Tris- $\mathrm{HCl}, 0.1 \mathrm{mM}$ EDTA, $\mathrm{pH} 7.5)$ and $5 \mu \mathrm{L}$ was used to perform polymerase chain reaction (increased up to $10 \mu \mathrm{L}$ when the amplification failed). Amplified fragments were analysed using an ABI 310 Genetic Analyzer (Applied Biosystems Inc., Foster City, CA, USA). The genotyping of adult trees was performed similarly, but with DNA extracted from leaf tissue. For further details on leaf and endocarp genotyping protocols, see Godoy \& Jordano (2001).

\section{DATA ANALYSIS}

\section{Identification of source trees contributing to the seed rain}

The source tree of dispersed seeds was identified by genotyping the endocarp, a tissue of maternal origin, and thus with an identical multilocus genotype to its source tree (Godoy \& Jordano 2001). As stated above, a set of nine microsatellite loci were considered for identifying the maternal tree for each endocarp. We assigned an adult tree as a maternal tree for a given endocarp when multilocus genotypes of the tree and the endocarp matched for all nine loci, or when they matched for eight loci but one missing locus (i.e. a locus with one or both missing alleles). One locus mismatches were allowed to account for the possibility of genotyping errors that are expected to be common when genotyping low-quality DNA sources, such as endocarp or pericarp tissues (Jordano 2007). When the source tree of a dispersed seed grew within the stand, it was unambiguously identified since all adult trees in the reference area were genotyped and all of them presented a distinct multilocus genotype. All adult trees produced fruits during the fruiting season (between mid-July and early-September). When the endocarp did not match any adult tree in the study site, we inferred a dispersal event from outside our study stand. However, our emphasis in this study was to identify each maternal tree within the study site rather than the population of origin (see García, Jordano \& Godoy 2007; Jordano 2007; Jordano et al. 2007 for details on dispersal distance patterns). Our previous studies reported a low probability of cryptic seed flow $\left(\mathrm{CSF}=10^{-7}\right)$ (i.e. the probability of assigning a seed to a local source tree whereas the actual source is located outside the population) (see García, Jordano \& Godoy 2007 for further details).

We used GIMLET software (Valière 2002) first to identify the different multilocus genotypes obtained for the endocarps and second, to find the matching adult multilocus genotype for each endocarp. In this way, we were able to estimate the minimum number of distinct maternal source trees contributing dispersed seeds to each seed trap. GIMLET also identifies those loci yielding null alleles due to allelelic dropout or scoring errors. To minimize the incidence of scoring errors, the scoring was performed by two different people independently. When doubts were cast on the authenticity of the allele, the loci were repeatedly amplified and ran in the sequencer (for protocol details on evaluating microsatellite markers, see Selkoe \& Toonen 2006). 
Table 1. Seed rain sampling for each microhabitat (left side of the table) and the maternal genetic correlation components (right side of the table). For each microhabitat type, we report the number of sample points, the total number of sampled seeds, the number of seeds per sample point (mean and error) and the observed number of contributing trees to each microhabitat, (maternal richness, $R$ ). The right side of the table reports the estimated mean and error values of the correlated maternity components for each microhabitat: (i) the maternal richness $(R$, mean number of maternal trees per seed trap); (ii) the maternal genetic relatedness $\left(r_{\text {in }}\right.$, genetic relatedness among maternal trees contributing to the same seed trap); (iii) and the probability of maternal identity (PMI, probability that two seeds randomly collected from the same seed trap come from the same mother tree). To estimate the correlated maternity components we only took into account those sample points with traps containing more than one dispersed seed

\begin{tabular}{|c|c|c|c|c|c|c|c|}
\hline \multirow[b]{2}{*}{$\begin{array}{l}\text { Microhabitat } \\
\text { type }\end{array}$} & \multicolumn{4}{|c|}{ Seed rain sampling } & \multicolumn{3}{|c|}{ Correlated maternity components } \\
\hline & $\begin{array}{l}\text { No. } \\
\text { sample } \\
\text { points }\end{array}$ & $\begin{array}{l}\text { No. } \\
\text { seeds } \\
\text { sampled }\end{array}$ & $\begin{array}{l}\text { Mean No. } \\
\text { seeds/sample } \\
\text { point }\end{array}$ & $\begin{array}{l}\text { Maternal } \\
\text { richness } \\
(R)\end{array}$ & $\begin{array}{l}\text { Mean } \\
\text { maternal } \\
\text { richness }(R)\end{array}$ & $\begin{array}{l}\text { Mean maternal } \\
\text { genetic } \\
\text { relatedness }\left(r_{\text {in }}\right)\end{array}$ & $\begin{array}{l}\text { Probability of } \\
\text { maternal } \\
\text { identity }(P M I)\end{array}$ \\
\hline МН-Prunus & 10 & 106 & $10.6 \pm 1.8$ & 50 & $3.40 \pm 0.34$ & $0.57 \pm 0.07$ & $0.41 \pm 0.01$ \\
\hline MH-High shrub & 42 & 194 & $4.6 \pm 0.6$ & 95 & $5.6 \pm 0.62$ & $0.33 \pm 0.04$ & $0.16 \pm 0.01$ \\
\hline MH-Low shrub & 11 & 19 & $1.7 \pm 0.4$ & 16 & $1.27 \pm 0.19$ & $0.18 \pm 0.07$ & $0.31 \pm 0.04$ \\
\hline МH-Pinus & 31 & 65 & $2.1 \pm 0.3$ & 46 & $1.71 \pm 0.21$ & $0.42 \pm 0.06$ & $0.18 \pm 0.01$ \\
\hline MH-Acer-Quercus & 32 & 39 & $1.2 \pm 0.2$ & 21 & $1.34 \pm 0.12$ & $0.47 \pm 0.09$ & $0.61 \pm 0.12$ \\
\hline MH-Open & 25 & 39 & $1.6 \pm 0.2$ & 27 & $1.32 \pm 0.11$ & $0.32 \pm 0.09$ & $0.23 \pm 0.05$ \\
\hline
\end{tabular}

\section{Distribution of the maternal seed progenies among microhabitats}

After identifying the trees contributing to the seed rain, we aimed at describing how different maternal trees distribute their progeny among microhabitats. We computed the frequency distribution of the number of contributed seeds per maternal tree in each microhabitat type and we tested for differences among microhabitats by applying a non-parametric Kruskal-Wallis test. Then, we estimated the maternal richness, i.e. the number of distinct maternal trees contributing seeds to each microhabitat. The uneven seed sample size among microhabitats made direct comparisons of the maternal richness values unreliable. To overcome this problem, we performed a sample-based rarefaction comparing the number of items (maternal contributing trees) observed in two or more seed samples with the same sampling effort. Basically, if we want to compare the number of maternal trees contributing with two different microhabitats receiving an unequal number of seeds, the rarefaction procedure extracts from both microhabitats random subsamples of the same size as that of the microhabitat receiving the lowest number of seeds. The number of observed mother trees for each subsample is recorded. This resampling is repeated 1000 times in both microhabitats and the mean number of mother trees observed in both subsamples is referred to as the mean rarefied maternal richness (see Hurlbert 1971 for further details on rarefaction methods and Petit, El Mousadik \& Pons 1998 for application in population genetics). We tested the effect of microhabitat type on the mean rarefied richness value by using a one-way ANova. Rarefaction analyses were performed by using simulations with EcoSim 7.71 software (Gotelli \& Entsminger 2005).

We used correspondence analysis (CA) to determine the associations between maternal progenies and microhabitat types, i.e. to assess whether specific groups of source trees disperse seeds non-randomly to certain microhabitats and whether microhabitats show similar patterns of seed rain composition in terms of contributing maternal trees. Using a Pearson's $\chi^{2}$-test, we checked the null hypothesis of independence between the two sets of data, i.e. the existence of a random association of groups of maternal trees and microhabitat types. In the CA plot, microhabitat types are grouped according to the similarity of their contributed progeny and, reciprocally, the trees are grouped according to their similarities in seed dispersal to the different microhabitats. Thus, the shorter the distance between two microhabitat types is, the higher the similarity of the pool of maternal trees contributing progeny to them; on the other hand, trees grouped together tend to show similar patterns of seed progeny dissemination across microhabitat types. We applied two Mantel tests to test for (i) a distance effect (nearby growing trees tending to disperse seeds to similar microhabitats); and (ii) the influence of the maternal neighbourhood (trees with similar maternal neighbourhood tending to disperse seeds to similar microhabitats, regardless of the distances among them). We first obtained a distance matrix (Matrix A) based on the Euclidean distance between the scores associated to each pair of maternal trees in the CA. We also obtained a distance matrix (Matrix B) containing the Euclidean distance between each pair of maternal trees in the population based on their geographical coordinates. We finally computed a dissimilarity matrix (Matrix C) describing how dissimilar each pair of maternal trees is in the characteristics of their maternal neighbourhoods (based on the Mahalanobis distance estimated from the physiognomic characteristics within a 30-m radius circle around the source trees). The first Mantel test examined the correlation between matrices $\mathbf{A}$ and $\mathbf{B}$ (i.e. Do maternal trees near each other tend to disperse their progeny to similar microhabitat types?). The second Mantel test checked the correlation between matrices $\mathbf{A}$ and $\mathbf{C}$ (i.e. Do source trees growing in similar maternal neighbourhoods tend to disperse their progeny to similar microhabitat types?). As the spatial distribution of the maternal neighbourhoods in the population might itself be autocorrelated (i.e. similar maternal neighbourhoods tend to be close together), we additionally performed a partial Mantel test (Smouse, Long \& Sokal 1986) to test the correlation between matrices $\mathbf{A}$ and $\mathbf{C}$, while controlling for the effect of geographical distance among source trees (matrix B). All Mantel tests were performed with the R package (R Development Core Team 2009).

\section{Maternal genetic correlations in the seed rain}

Besides the distribution pattern of maternal progenies among microhabitat types that might result in differences in maternal richness values among microhabitats, another aspect of the maternal genetic correlations is the genetic relatedness among source trees contributing to the same seed trap. We assessed the genetic relatedness among trees contributing seeds to the same $\left(r_{\text {in }}\right)$ and to different seed traps $\left(r_{\text {out }}\right)$. 
We estimated relatedness, i.e. the probability that two individuals share an identical allele by descent, following Queller \& Goodnight (1989) with SPAGeDi 1.2 (Hardy \& Vekemans 2002). A significantly higher $r_{\text {in }}$ relative to $r_{\text {out }}$ would be an evidence of a spatial aggregation of maternally related seeds at the seed-trap level. We used a KruskalWallis test to assess if $r_{\text {in }}$ significantly exceeds $r_{\text {out }}$, as expected if seed progeny from related source trees tends to be dispersed to the same seed traps.

Finally, we estimated the correlated maternity among seeds within the same trap, i.e. the probability for two seeds drawn from the same seed trap to be maternal half-sibs. This term is analogous to correlated paternity (proportion of full-sib seeds within a sibship, Ritland 1989). Following the same analytical approach as in Grivet, Smouse \& Sork (2005) to study acorn dispersal in Quercus lobata, we assessed correlated maternity as the probability of maternal identity (PMI), i.e. the probability that two given seeds drawn at random from the same seed trap have the same mother. This approach is based on the probability of paternal identity (PPI) proposed by Smouse \& Robledo-Arnuncio (2005) that estimates the probability of two seeds drawn at random from the same mother tree having the same father. Thus, in our study, for each seed trap receiving two or more seeds, we compute PMI as:

$r_{g}=\sum_{K=1}^{K} \frac{x_{g k}\left(x_{g k}-1\right)}{n_{g}\left(n_{g}-1\right)}$

where $n_{g}$ is the number of seeds in the gth seed trap, and $x_{g k}$ is the number of seeds provided by the $k$ th mother, with

$\sum_{K=1}^{K} x_{g k}=n_{g}$

This is the least biased PMI estimator for small-sample sizes (see Grivet, Smouse \& Sork 2005 for further details and a discussion of two different PMI estimators). The PMI ranges between 0 (all seeds within a seed trap come from different source trees) and 1 (all seeds within a seed trap come from the same source tree).

\section{Ecological and spatial factors influencing maternal genetic correlation patterns in the seed rain}

Finally, we explored the influence of the spatial features linked to the location of the seed traps in the landscape on determining the maternal genetic correlation values. We applied two linear mixed-effect models fitted by Residual Maximum Likelihood Estimation that included maternal richness, maternal relatedness and correlated maternity as dependent variables and seed trap as a random factor. As explanatory variables we included a set of variables describing the spatial features of the deposition site: (i) the microhabitat type where the seed trap was located; (ii) the distance from each the seed trap to its nearest $P$. mahaleb tree (DNT); (iii) the azimuth (the deviation in degrees from the North) from each seed trap to its nearest $P$. mahaleb tree, (ANT); and (iv) the Dirichlet tile area computed at its nearest tree (DIR.AREA). To take into account the spatial autocorrelation of the maternal genetic correlation (i.e. the trend for nearby seed traps presenting similar values of maternal genetic correlations), we fitted two models: Model 1, where the errors are considered independent and evenly distributed, and Model 2, where the spatial structure of the errors is taken into account (assuming an autoregressive correlation structure) by including the spatial coordinates of the seed traps (see Crawley 2002 for details). For a thorough discussion of spatially non-independent models, see Keitt et al. (2002). Selection between these two models was based on the differences in Akaike's Informa- tion Criterion (AIC) (the lower the value of the AIC, the better the fitting of the model to the observed data), along with the $P$-value associated with the likelihood-ratio test between Models 1 and 2 (Crawley 2002). We used the R package both to fit the models and to select the best-fitted model (library nlme) (R Development Core Team 2009).

\section{Results}

IDENTIFICATION OF SOURCE TREES AND

DISTRIBUTION OF THE MATERNAL PROGENIES

AMONG MICROHABITATS

We identified 153 different trees contributing one or more of the 462 seeds whose endocarp genotypes unequivocally matched those of their maternal source trees. Among them, 139 were local source trees and 14 were source trees located outside the population. We observed that most source trees contributed with a single seed dispersal event to a given microhabitat (Fig. 1). The frequency distribution of the number of seeds contributed per maternal tree varied significantly among microhabitats (Kruskall-Wallis, $\chi^{2}=18.36$, d.f. $=5, P<$ $0.01)$. The highest contribution per source tree was observed in $\mathrm{MH}-$ Prunus and $\mathrm{MH}$-high shrub, where few trees contributed up to 10 seeds, whereas in $\mathrm{MH}$-open and $\mathrm{MH}$-low shrub most trees contributed up to a maximum of three seeds per tree.

There was a general trend for maternal richness $(R)$ to increase with the number of seeds sampled in a given microhabitat (Table 1, Fig. 2) implying that most contributed seeds came from different source trees, instead of most coming from a few sources. After rarefying the seed sample (Fig. 2), we compared the mean rarefied values among microhabitat types for a sample size of $n=19$ (the lowest seed sample size that corresponded to $\mathrm{MH}$-low shrub). We found significant differences among microhabitats for mean rarefied richness values $(F=183.43$, d.f. $=5, P<0.001)$, the lowest mean value corresponded to MH-Prunus $(10.64 \pm 0.04)$ and the highest mean value to $\mathrm{MH}$-high shrub $(15.83 \pm 0.04)$. Thus, for seed sample sizes as small as $n=19$, an average of 10 distinct mother trees were contributing to MH-Prunus, whereas an average close to 16 distinct mother trees were contributing to MH-high shrub.

The CA showed a non-random distribution of maternal progenies among the different microhabitat types $\left(\chi^{2}=1173.88\right.$, d.f. $\left.=1260, P<0.05\right)$, with the first two axes $\mathrm{C} 1$ (eigenvalue $=0.80$ ) and $\mathrm{C} 2$ (eigenvalue $=0.41$ ), accounting for $81.85 \%$ of the variance (inertia in CA terms). Figure 3 shows the correspondence plot displaying the scores for microhabitat types and maternal trees in a two-dimensional space given by $\mathrm{C} 1$ and $\mathrm{C} 2$. In the correspondence plot (Fig. 3), distance among microhabitats is proportional to the dissimilarity of the composition of their maternal progenies. Note that microhabitat types dominated by fleshy-fruited species have a more similar array of maternal progenies (corresponding to microhabitats with negative scores on $\mathrm{C} 1$ ). This implies that the pools of maternal progenies reaching a fleshy-fruited microhabitat resemble each other. Similarly, the proximity in 


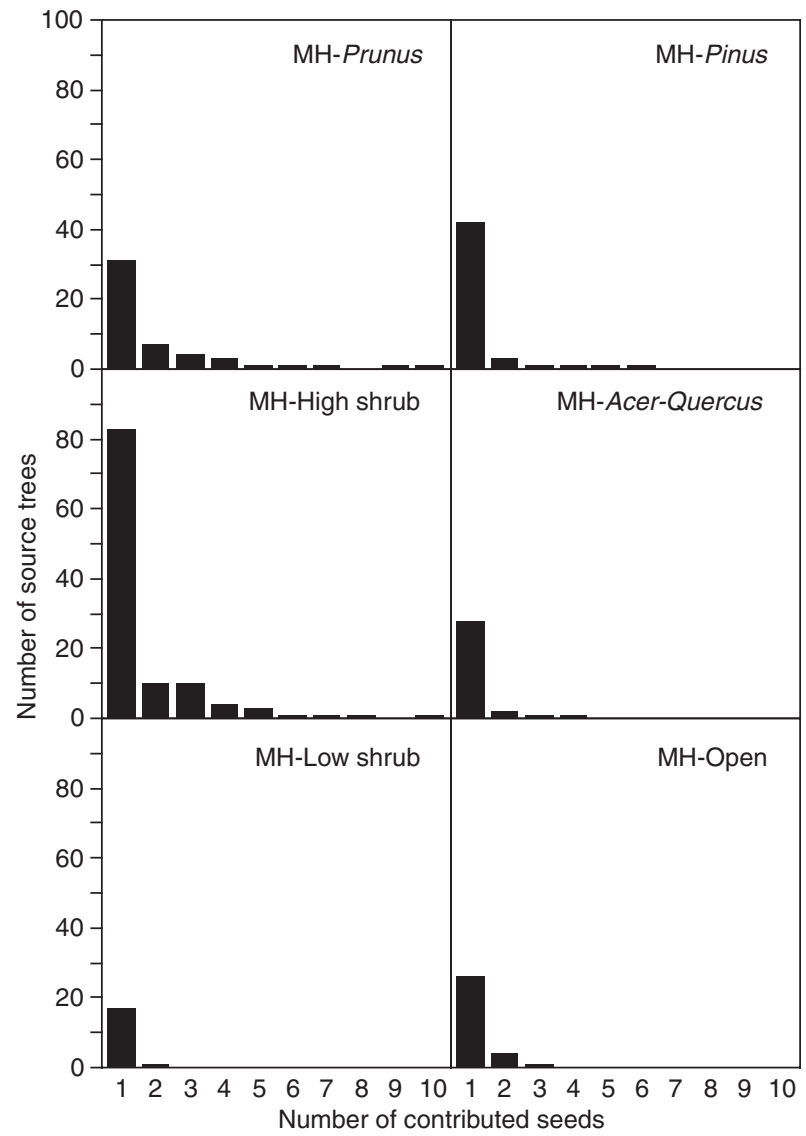

Fig. 1. Frequency distribution of the number of seeds dispersed from distinct maternal trees in the seed rain at each microhabitat (MH) type. Note that most source trees contributed only one seed, except in $\mathrm{MH}-$ Prunus and MH-High shrub, where individual source trees can contribute up to 10 seeds. Microhabitats $(\mathrm{MH})$ where seed traps were located are classified based on physiognomic features: (i) MH-Prunus, beneath P. mahaleb trees; (ii) MH-Pinus beneath pines; (iii) MH-High shrub is dominated woody species reaching over $1.5 \mathrm{~m}$ height; MHAcer-Quercus, beneath maple and oaks species (non-fleshy fruited species); (iv) MH-Low shrub is dominated by woody species under $1.5 \mathrm{~m}$ height; and (v) MH-Open includes rocky outcrops and grassland. the correspondence plot of the microhabitats dominated by pine trees and open vegetation (MH-Pinus and $\mathrm{MH}$-open) indicated similar profiles of maternal progenies in these two microhabitat types. The isolated location of $\mathrm{MH}$-Acer-Quercus in the graph indicates that this microhabitat received a distinctive pool of maternal progenies.

Our results show that certain microhabitat types received similar arrays of maternal progenies whereas others contained quite distinctive ones. One likely explanation for this is that the nearby fruiting trees contributed to the same microhabitat types. However, we did not find a significant correlation between the geographical distance and the distance in the ordination space defined by axes $\mathrm{C} 1$ and $\mathrm{C} 2$ among maternal trees (Mantel test, $r=-0.0055, P=0.10$ ). More interestingly, we observed a significant correlation between the distance among trees in the correspondence map and the similarity of their maternal neighbourhoods (Matrices A and C, Mantel test, $r=0.454, P=0.001)$. This correlation remained significant when we controlled for the geographical distance among contributing trees (Partial Mantel test, $\mathrm{r}=0.189, P=0.01$ ). In other words, among all available progenies in the population, microhabitat types received different non-randomly assorted sets of maternal progenies; progenies from maternal trees with similar maternal neighbourhoods tended to reach similar microhabitats.

\section{MATERNAL GENETIC CORRELATIONS IN THE SEED RAIN}

We observed higher mean relatedness among maternal trees contributing dispersed seed to the same seed trap $\left(r_{\text {in }}\right)$ than among maternal trees contributing to different seed traps $\left(r_{\text {out }}\right)$ (Kruskall-Wallis $H=19.11$, d.f. $=1, P<0.001$ ) indicating a spatial aggregation of maternally related propagules in the seed traps. The mean $r_{\text {in }}$ values doubled the mean $r_{\text {out }}$ values $\left(r_{\text {in }}=0.4047 \pm 0.0005\right.$ and $\left.r_{\text {out }}=0.2273 \pm 0.0046\right)$. Mean $r_{\text {in }}$ values differed among microhabitat types (Kruskall-Wallis $H=13.61$, d.f. $=5, P<0.05$ ), with the highest mean $r_{\text {in }}$ values found in MH-Prunus and MH-Acer-Quercus (Table 1).

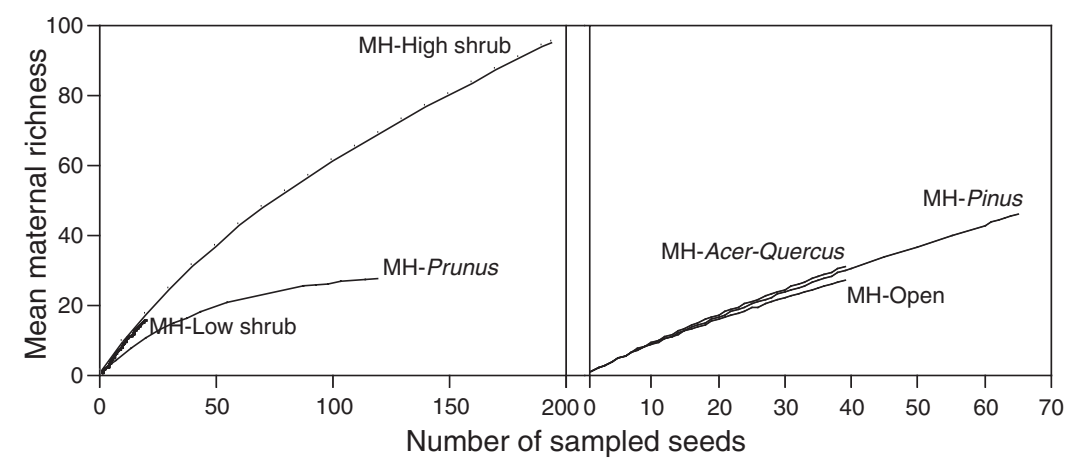

Fig. 2. Rarefaction curves showing the increase of mean richness of maternal genotypes per sampled seed from the total seed sample per microhabitat. We performed 1000 simulations for each microhabitat. To improve clarity, the curves for sampling sites beneath fleshy-fruited and nonfleshy fruited microhabitats are plotted separately. Microhabitats (MH) are classified based on physiognomic features: (i) MH-Prunus, beneath P. mahaleb trees; (ii) MH-Pinus beneath pines; (iii) MH-High shrub is dominated woody species reaching over $1.5 \mathrm{~m}$ height; MH-Acer-Quercus, beneath maple and oaks species (non-fleshy fruited species); (iv) MH-Low shrub is dominated by woody species under $1.5 \mathrm{~m}$ height; and (v) MH-Open includes rocky outcrops and grassland. 


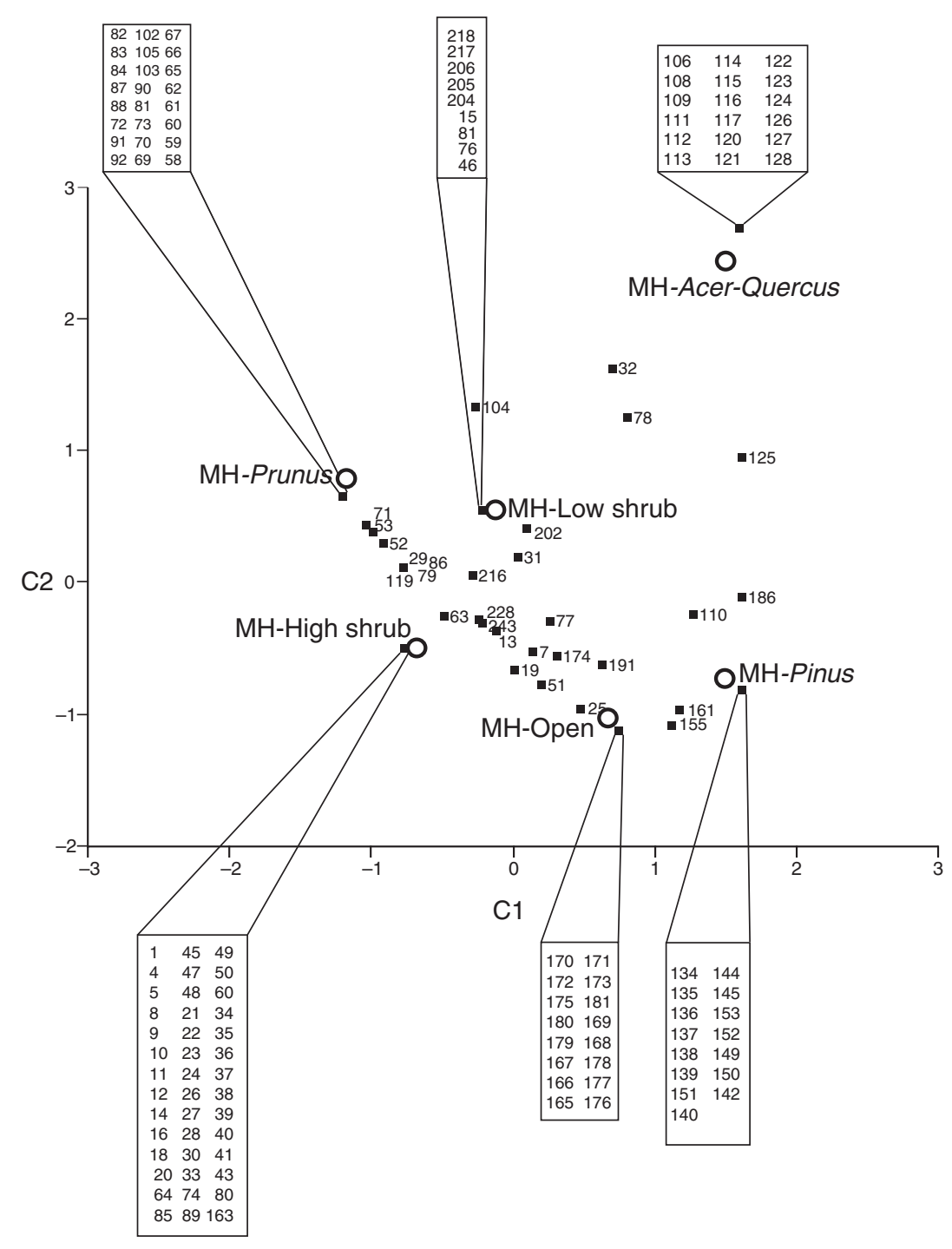

Fig. 3. Results of the correspondence analysis (CA) depicting the reciprocal ordination of maternal progenies in the seed rain (squares) and microhabitat types (blank dots). The analysis groups individual source trees according to their similarities in seed delivery to different microhabitats, and groups microhabitats according to similarities in the trees that contribute seeds to them. Figures indicate the identification code of maternal trees, with those that overlap in a given coordinate on the plot grouped within rectangles. Note that squares located near a given microhabitat type group maternal progenies that tend to be recurrently dispersed to that specific microhabitat. Microhabitats located nearby in the figure received progeny from a similar pool of maternal trees, whereas distant microhabitats receive progeny from scarcely overlapping sets of maternal trees. Note that microhabitats dominated by fleshy-fruited species tended to have similar pools of mother trees contributing progeny, with little overlap with the pool of mother trees contributing progeny to those microhabitats dominated by non-fleshy fruits. Microhabitats are classified based on physiognomic features: (i) MH-Prunus, beneath P. mahaleb trees; (ii) MH-Pinus beneath pines; (iii) MH-High shrub is dominated woody species reaching over $1.5 \mathrm{~m}$ height; MH-Acer-Quercus, beneath maple and oaks species (non-fleshy fruited species); (iv) MH-Low shrub is dominated by woody species under $1.5 \mathrm{~m}$ height; and (v) MH-Open includes rocky outcrops and grassland.

Mean $r_{\text {in }}$ values correlated negatively with the geographical distance among maternal trees $\left(r=-0.224, R^{2}=0.403\right.$, $P<0.001$ ), indicating that seed traps with seeds of a high maternal relatedness tended to receive seeds from nearby trees. Note that nearby trees tend to be genetically related in spatially structured populations, as in this study population where adult trees show this trend up to $30 \mathrm{~m}$ distance (see Jordano \& Godoy 2002). Finally, mean PMI values differed among microhabitats (Kruskall-Wallis $H=16.24$, d.f. $=5, P<0.01$ ), with the highest values observed in MH-Acer-Quercus $(0.61 \pm 0.12)$ followed by MH-Prunus $(0.41 \pm 0.012)$ and the lowest values found in MH-High shrub. These results indicate that seed traps located in MH-Acer-Quercus and MH-Prunus received a higher proportion of propagules coming from the same source tree than seed traps located in other microhabitats.

\section{ECOLOGICAL AND SPATIAL FACTORS INFLUENCING MATERNAL GENETIC CORRELATION PATTERNS IN THE SEED RAIN}

Model 2 (taking into account the spatial covariance of the errors) fitted our data better than Model 1 (which assumed 
spatially independent errors) for all maternal genetic correlations components, as indicated by its significantly lower AIC value (Table 2). This result suggests a spatial covariation of the maternal genetic correlation components in the seed rain. Furthermore, by applying Model 2 the effect of some spatial variables became marginally significant, despite their nonsignificance when applying Model 1 (Table 2). This is the case for DNT on the effect of correlated maternity and DIR.AREA on the effect of maternal richness (Table 2). In Model 2, correlated maternity tended to increase marginally with decreasing distance to the nearest $P$. mahaleb tree, indicating a spatial aggregation of maternally related seeds nearby fruiting trees. Similarly, the seeds in seed traps located in a cluster of fruiting trees (small DIR.AREA) tended to show marginally larger values of maternal richness relative to more isolated trees.

\section{Discussion}

The application of molecular markers to seed-dispersal ecology allows the study of maternal genetic correlations in the seed rain (i.e. the richness of maternal trees contributing to the seed rain, their genetic relatedness and the probability of maternal progenies to be dispersed to the same deposition sites). By identifying the source tree of dispersed seeds, we reported a non-random distribution of maternal progenies in a frugivore-generated seed rain. This pattern is characterized by a significant non-random association between groups of maternal trees with similar maternal neighbourhoods and certain microhabitat types. Additionally, we observed a spatial aggregation of maternally related progenies in the seed traps, strongly determined by the microhabitat type and marginally influenced by other spatial traits linked to the location of the seed trap. Thus, our results evidenced that highly selective foraging by frugivorous vertebrates in heterogeneous landscapes results in a genetic limitation, i.e. the failure of maternal trees to reach all microhabitat types, as well as the failure of the microhabitat types to cast all maternal progenies. These seed progenies become locally distributed as maternally related aggregates at the seed-trap level. Differential deposition patterns among microhabitats by frugivorous vertebrates yielded a wide variation of maternal genetic correlations, generating an overall complex pattern of maternal genetic correlations in the landscape.

\section{GENETIC LIMITATION AND NON-RANDOM \\ DISTRIBUTION OF MATERNAL PROGENIES IN A \\ VERTEBRATE-GENERATED SEED RAIN}

The non-random distribution of maternal progenies among microhabitat types strongly reflected differences in the guild of dispersers visiting each microhabitat. Microhabitat types with fleshy-fruited species (MH-High shrub, MH-Low shrub, MH-Prunus) presented a similar pool of maternal progenies among them, and the same is true for MH-Pinus and $\mathrm{MH}-\mathrm{Open}$. This is the consequence of the selective foraging behaviour patterns of frugivorous birds that preferentially visit fleshy-fruited microhabitat types to feed, mobilizing a large number of seeds among these microhabitats (Jordano \& Schupp 2000). In contrast, seed rain in the pine forest, where rocky microsites (MH-Open) are also frequent, is mainly contributed to by mistle thrushes resulting in a different pool of maternal progenies compared with the fleshy-fruited microhabitats (Jordano \& Schupp 2000). More interesting, our results suggested that the similarity of the composition of maternal progenies dispersed at two given microhabitats tended to correlate with the similarity of the characteristics of the maternal neighbourhoods where the contributing trees grew up. Therefore, differences in the frugivore guild composition visiting different microhabitat types resulted in a non-random assortment of maternal progenies among microhabitats. Furthermore, selective foraging patterns derived in a strong resemblance of maternal progenies among preferred microhabitats, driven by likely recurrent visits from certain maternal trees (those with similar maternal neighbourhoods).

Our work, thus, shows a link between the characteristics of the ecological maternal neighbourhood and the microhabitat type where maternal trees disperse their progeny. Maternal neighbourhood characteristics are reported to influence the number of frugivorous species removing fruits, the rate at which these species remove fruits (García et al. 2001) and the shape of the resulting seed dispersal kernel (Carlo 2005; Morales \& Carlo 2006). Our results indicate that the influence of the maternal neighbourhood can be extended to the deposition pattern of the maternal progenies among microhabitats in the landscape. As a consequence, seed dispersal by frugivores in heterogeneous landscapes derives in a genetic limitation, i.e. a fourth type of limitation in addition to previously described numerical, distance and spatial limitations (Clark et al. 1999; Jordano \& Godoy 2002). The genetic limitation would arise from the distinctive composition of frugivore guilds visiting different microhabitat types coupled with strong foraging preferences that favour seed dispersal of maternal progenies from source trees growing at certain maternal neighbourhoods.

\section{MATERNAL GENETIC CORRELATIONS IN THE SEED RAIN}

Frugivore activity resulted in a strong spatial aggregation of maternally related progenies at the deposition sites (seed traps). Thus, seeds deposited in the same seed trap tended to be maternally correlated (i.e. they had a high probability of being maternal half-sibs) or to yield increased levels of maternal relatedness among contributing trees (i.e. genetically related trees contribute seed to the same seed trap). An expected mechanism of aggregating maternally related seeds is distance limitation, i.e. seed traps would tend to collect a high number of maternal progenies from the nearest fruiting trees. However, our results suggest that the maternal genetic correlations arose from distinctive dispersal patterns to different microhabitats. Figure 4 aims to illustrate this point by showing how different maternal genetic correlation values can emerge from distinct seed dispersal patterns driven by frugivore activity. The figure depicts the three study microhabitats (MH-Acer-Quercus, MH-Pinus, and MH-Low 
Table 2. (a) Statistical comparison between the two models used to test spatial effects on maternal genetic correlations components: (i) maternal richness (mean number of maternal trees per seed trap); (ii) maternal relatedness (genetic relatedness among maternal trees contributing to the same seed trap); and (iii) correlated maternity (probability that two seeds randomly collected from the same seed trap come from the same mother tree). Model 1 treats the errors as spatially independent whereas Model 2 considers their spatial covariance. Significantly lower AIC values in Model 2 suggest a better performance of this spatially expicit model compared to Model 1. (b) Effect of the spatial features linked to the seed trap locations on the maternal genetic correlations: MH, microhabitat type; DNT, distance to the nearest conspecific tree; AZT, azimut to the nearest conspecific tree; and DIR.AREA, area of the Dirichlet tile where the seed trap is located. We report the t-value, and the $P$-value associated to each variable for Models 1 and 2. Only significant or marginally significant variables are shown

\begin{tabular}{|c|c|c|c|c|}
\hline \multirow{2}{*}{$\begin{array}{l}\text { Maternal genetic } \\
\text { correlation component }\end{array}$} & \multirow{2}{*}{$\frac{\text { Model } 1}{\mathrm{AIC}}$} & \multicolumn{3}{|l|}{ Model 2} \\
\hline & & AIC & $\begin{array}{l}\text { L1kelihood } \\
\text { ratio test }\end{array}$ & $P$-value \\
\hline \multicolumn{5}{|l|}{ (a) Comparison of model fits } \\
\hline Maternal richness & 724.53 & 719.47 & 4.41 & $<0.05$ \\
\hline Maternal relatedness & 158.58 & 76.42 & 17.78 & $<0.05$ \\
\hline Correlated maternity & 121.28 & 95.13 & 24.17 & $<0.05$ \\
\hline
\end{tabular}

\begin{tabular}{|c|c|c|c|c|}
\hline $\begin{array}{l}\text { Maternal genetic } \\
\text { correlation component }\end{array}$ & $\begin{array}{l}\text { Spatial } \\
\text { variable }\end{array}$ & $\begin{array}{l}\text { Model } \\
\text { type }\end{array}$ & t-value & $P$-value \\
\hline \multicolumn{5}{|c|}{ (b) Factor effects on the maternal genetic correlations components } \\
\hline \multirow[t]{8}{*}{ Maternal richness } & $\mathrm{MH}$ & Model 1 & 49.02 & $<0.01$ \\
\hline & & Model 2 & - & - \\
\hline & DNT & Model 1 & 0.12 & $>0.05$ \\
\hline & & Model 2 & - & - \\
\hline & ANT & Model 1 & 0.15 & $>0.05$ \\
\hline & & Model 2 & - & - \\
\hline & DIR.AREA & Model 1 & 1.60 & $<0.05$ \\
\hline & & Model 2 & 3.08 & 0.08 \\
\hline \multirow[t]{8}{*}{ Maternal relatedness } & $\mathrm{MH}$ & Model 1 & 42.23 & $<0.01$ \\
\hline & & Model 2 & - & - \\
\hline & DNT & Model 1 & - & - \\
\hline & & Model 2 & - & - \\
\hline & ANT & Model 1 & - & - \\
\hline & & Model 2 & - & - \\
\hline & DIR.AREA & Model 1 & - & - \\
\hline & & Model 2 & - & - \\
\hline \multirow[t]{8}{*}{ Correlated maternity } & MH & Model 1 & 13.04 & $<0.01$ \\
\hline & & Model 2 & - & - \\
\hline & DNT & Model 1 & - & - \\
\hline & & Model 2 & 2.89 & 0.09 \\
\hline & ANT & Model 1 & - & - \\
\hline & & Model 2 & - & - \\
\hline & DIR.AREA & Model 1 & - & - \\
\hline & & Model 2 & - & - \\
\hline
\end{tabular}

shrub) where we observed contrasting patterns of maternal genetic correlations. Note that all three microhabitats differ in three key aspects: (i) how far contributing trees are located from the seed traps; (ii) how clumped the contributing trees are arranged; and (iii) the frugivorous bird assemblage visiting them (based on Jordano \& Schupp 2000). Thus, coherent with the dominant dispersal patterns previously reported (Jordano \& Schupp 2000), we observed high mean maternal genetic relatedness in $\mathrm{MH}$-Acer-Quercus due to a high correlated maternity coupled with low maternal richness involving recurrent seed dispersal from the same maternal tree to the same deposition site (Fig. 4). Seed traps located in MH-Pinus presented increased values of maternal richness coupled with high mean maternal genetic relatedness, but low mean corre- lated maternity values (Fig. 4). This pattern is generated by large groups of mistle thrushes recurrently flying from clusters of $P$. mahaleb trees to pine trees, which explains the high relatedness values (since the birds tend to visit nearby trees) but low correlated maternity values (as this seed rain is contributed by several source trees). Additionally, high values of maternal richness and low values of relatedness and correlated maternity are possible when seed dispersal is very active and is assisted by a wide range of frugivorous birds favouring highly overlapping seed shadows as in MH-High shrub (not included in the figure). Seed traps located in MH-Low shrub presented low maternal diversity and both low relatedness and correlated maternity. This pattern suggests that seed rain under low shrubs comes from few source trees (due to 


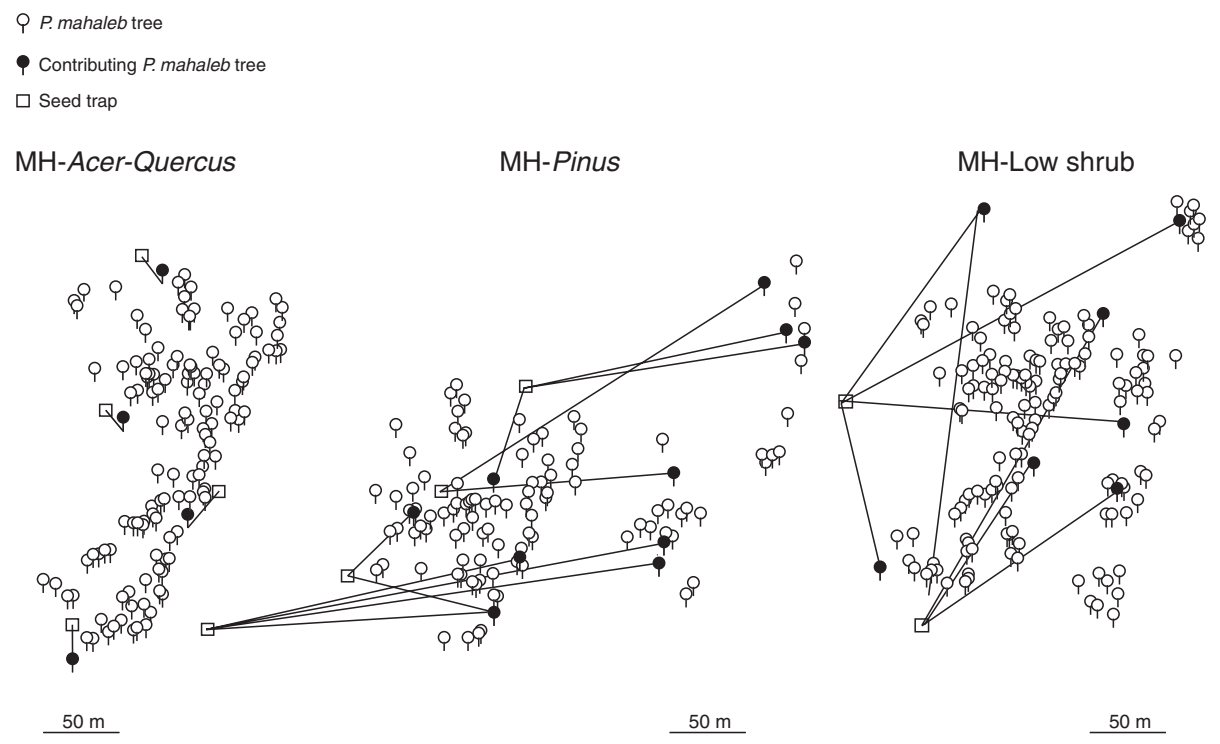

Fig. 4. Illustrative examples of different dispersal patterns observed in microhabitats of the study population. The map shows the locations of $P$. mahaleb trees (black dots) contributing seeds to the same seed trap (open squares). Lines indicate dispersal events. Left panel illustrates a typical pattern in MH-Acer-Quercus, (seed traps with Acer spp. and/or Quercus spp. cover); middle panel illustrates MH-Pinus microhabitat (cover by Pinus nigra subsp. salzmanii); and right panel illustrates MH-Low shrub microhabitat (covered by low shrub species). Seeds dispersed to MHAcer-Quercus tended to come from a single source tree (resulting in high mean correlated maternity); seed progenies deposited in MH-Pinus tended to come from different source trees growing closely, but located far away from the seed trap (resulting in high mean relatedness but low correlated maternity values); seeds in MH-Low shrub tended to come from different and distant maternal trees (low mean correlated maternity and low mean relatedness values). Note that the figure does not represent the whole population but only relevant sections illustrating variation of the maternal genetic correlation components among microhabitats.

low frequency of dispersed seeds) located at variable distances from the seed trap (Fig. 4). MH-Low shrub patches are visited by small passerine species whose feeding behaviour favoured the deposition of seeds from different mother trees not necessarily located in the neighbourhood of the seed trap, but spread over the landscape at variable distances (Jordano \& Schupp 2000). Finally, we also observed high maternal relatedness and correlated maternity values in seed traps under $P$. mahaleb trees, as expected due to the effect of the source tree. Therefore, besides the variation of the maternal genetic correlations over the landscape, mainly due to differences in the guild of frugivores visiting each microhabitat type, this study demonstrates that high maternal genetic correlation values might arise from: (i) frequent seed dispersal from trees near the seed trap (involving frequent short-distance dispersal) as observed in MH-Prunus, and (ii) frequent dispersal events from distant clusters of trees (involving frequent long-distance dispersal), as observed in MH-Pinus. Previously, Grivet, Smouse \& Sork (2005) also documented a maternal aggregation of acorns in granaries where birds (Melanerpes formicivorus) deposit multiple acorns from few mother trees $\left(N_{\mathrm{e}} \sim 2\right)$ in a valley oak (Q. lobata) population. This foraging behaviour where the birds defend the granaries within their territories coupled with a strongly leptokurtic seed dispersal kernel resulted in a little overlapping of maternal trees contributing to different granaries. This study together with our results points out that the consequences of dispersal by frugivores transcend seed demographic and distance limitation effects by distributing maternal progeny non-randomly and in a highly structured mode among available deposition sites. As for the genetic consequences of this maternal aggregation observed among dispersed propagules, Torimaru et al. (2007) documented that the marked spatial genetic structure recorded in Ilex leucoclada, a multi-seeded species dispersed by frugivorous birds, results from the combined effect of dispersal limitation coupled with kin-structured dispersal. Our findings emphasize that kin-structured dispersal results from the combined effect of the maternal trees growing sites (physiognomic characteristics), distance effects and frugivore foraging preferences. This appears to be the characteristic imprint of complex seed shadows generated by diverse coteries of frugivorous animals in heterogeneous landscapes.

\section{UNDERSTANDING THE CONSEQUENCES OF VERTEBRATE SEED DISPERSAL FOR RECRUITMENT IN PLANT POPULATIONS}

The combined information provided by molecular markers to track seed dispersal events, the detailed knowledge of frugivore foraging preferences and a fine characterization of the ecological landscape features allow tackling seed dispersal studies with two rarely combined approaches: (i) the seed rain approach (How do dispersed propagules reach a specific deposition point in the landscape?) and (ii) the maternal tree approach (Where do maternal trees disperse their progeny?). Our study presents evidence that both approaches yield valuable complementary information and only by combining them within a unified framework, we will gain a comprehensive picture of the consequences of seed dispersal by frugivores. First, we documented 
that different microhabitats received non-randomly assorted sets of maternal progenies and that maternally related progenies become spatially aggregated. Thus, dispersal distance limitation is not the only mechanism causing an aggregation of maternal progenies, but markedly selective foraging patterns by frugivores in heterogeneous landscapes might produce similar deposition patterns of maternal progenies. Consequently, strong patterns of local genetic differentiation would emerge in heterogeneous landscapes as a result of frugivore activity in spite of active dispersal that frequently involves long-distance dispersal events. As reported for bird populations, a non-random dispersal pattern is the first step towards the spatial and genetic differentiation in heterogeneous natural landscapes (Garant et al. 2005). In addition, this represents a highly effective mechanism maintaining the spatial and genetic differences among patches at very fine spatial scales in environmentally heterogeneous areas (Postma \& van Noordwijk 2005). Understanding the outcomes of mutualistic interactions during plant recruitment will require elucidating how maternally structured seed rain in heterogeneous landscapes contributes to effective regeneration and how animal frugivores influence this process.

\section{Acknowledgements}

We are in debt with J.L. García-Castaño, J.G.P. Rodríguez and M. Carrión for their assistance with exhaustive field work, and with C. Rigueiro for help in the laboratory. D. García, X. Pico and V.L. Sork, the members of the Integrative Ecology Group at Estación Biológica de Doñana (http://www.ieg.ebd.csic.es), and two anonymous referees greatly improved drafts of the manuscript with their useful comments. The Consejería de Medio Ambiente (Junta de Andalucía) greatly facilitated our work in Parque Natural de las Sierras de Cazorla Segura y Las Villas. Our work was funded by grants REN2003-00273 and CGL2006-00373 from the Spanish Ministerio de Educación y Ciencia (MEC) and P07-RNM-02824 from the Junta de Andalucía; C.G. was funded by a MCyT research grant (FP2000-5627).

\section{References}

Augspurger, C.K. \& Kitajima, K. (1992) Experimental studies of seedling recruitment from contrasting seed distributions. Ecology, 73, 1270-1284.

Carlo, T.A. (2005) Interspecific neighbors change seed dispersal pattern of an avian-dispersed plant. Ecology, 86, 2440-2449.

Cheung, W.Y., Hubert, N. \& Landry, B.S. (1993) A simple and rapid DNA microextraction method for plant, animal, and insect suitable for RAPD and PCR analyses. PCR Methods and Applications, 3, 69-70.

Clark, J.S., Beckage, B., Camill, P., Cleveland, B., HilleRisLambers, J., Lighter, J., McLachlan, J., Mohan, J. \& Wyckoff, P. (1999) Interpreting recruitment limitation in forests. American Journal of Botany, 86, 1-16.

Crawley, M.J. (2002) Statistical Computing: An Introduction to Data Analysis Using S-Plus. John Wiley \& Sons, Chichester.

Donohue, K. (2003) The influence of neighbor relatedness on multilevel selection in the Great Lakes sea rocket. American Naturalist, 162, 77-92.

Epperson, B.K. \& Álvarez-Buylla, E. (1997) Limited seed dispersal and genetic structure in life stages of Cecropia obtusifolia. Evolution, 51, 275-282.

Garant, D., Kruuk, L.E.B., Wilkin, T.A., McCleery, R.H. \& Sheldon, B.C. (2005) Evolution driven by differential dispersal within a wild bird population. Nature, 433, 60-65.

García, C., Jordano, P. \& Godoy, J.A. (2007) Contemporary pollen and seed dispersal in a Prunus mahaleb population: patterns in distance and direction. Molecular Ecology, 16, 1947-1955.

García, D., Zamora, R., Gómez, J.M. \& Hódar, J.A. (2001) Frugivory at Juniperus communis depends more on population characteristics than on individual attributes. Journal of Ecology, 89, 639-647.

García, C., Arroyo, J.M., Godoy, J.A. \& Jordano, P. (2005) Mating patterns, pollen dispersal, and the ecological maternal neighbourhood in a Prunus mahaleb L. population. Molecular Ecology, 14, 1821-1830.
García-Castaño, J.L. (2001) Consecuencias Demográficas de la Dispersión de Semillas por Aves y Mamiferos Frugivoros en la Vegetación Mediterránea de Montaña. PhD Thesis, Universidad de Sevilla, Sevilla, Spain.

Godoy, J.A. \& Jordano, P. (2001) Seed dispersal by animals: exact identification of source trees with endocarp DNA microsatellites. Molecular Ecology, 10, 2275-2283.

Gotelli, N.J. \& Entsminger, G.L. (2005) Ecosim: Null Models Software for Ecology. Acquired Intelligence Inc. \& Kesey-Bear, Jericho, VT, USA.

Grivet, D., Smouse, P.E. \& Sork, V.L. (2005) A novel approach to an old problem: tracking dispersed seeds. Molecular Ecology, 14, 3585-3595.

Hampe, A., García-Castaño, J.L., Schupp, E.W. \& Jordano, P. (2008) Initial recruitment of vertebrate-dispersed woody plants: a spatially explicit analysis across years. Journal of Ecology, 96, 668-678.

Hamrick, J.L., Murawski, D.A. \& Nason, J.D. (1993) The influence of seed dispersal mechanisms on the genetic structure of tropical tree populations. Vegetatio, 107/108, 281-297.

Hardy, O.J. \& Vekemans, X. (2002) SPAGeDi: a versatile computer program to analyse spatial genetic structure at the individual or population levels. Molecular Ecology Notes, 2, 618-620.

Howe, H.F. \& Smallwood, J. (1982) Ecology of seed dispersal. Annual Review of Ecology and Systematics, 13, 201-228.

Hubbell, S. (2001) The Unified Neutral Theory of Biodiversity and Biogeography. Princeton University Press, Princeton, USA.

Hurlbert, S.H. (1971) Pseudorreplication and design of ecological field experiments. Ecological Monographs, 54, 187-211.

Jones, A.F., Chen, J., Weng, G.J. \& Hubbell, S.P. (2005) A genetic evaluation of seed dispersal in the neotropical tree Jacaranda copaia (Bignonaceae). American Naturalist, 166, 543-555.

Jordano, P. (2007) Frugivores, seeds, and genes: analysing the key components of seed shadows. Seed Dispersal: Theory and its Applications in a Changing World (eds A.J. Dennis, E.W. Schupp, R.J. Green \& D.A. Westcott), pp. 229-251. CAB International, Wallingford, UK.

Jordano, P. \& Godoy, J.A. (2002) Frugivore-generated seed shadows: a landscape view of the demographic and genetic effects. Seed Dispersal and Frugivory: Ecology, Evolution and Conservation (eds D.J. Levey, W.R. Silva \& M. Galetti), pp. 305-321, CAB International, Wallingford, UK.

Jordano, P. \& Schupp, E.W. (2000) Seed disperser effectiveness: the quantity component and patterns of seed rain for Prunus mahaleb. Ecological Monographs, 70, 591-615

Jordano, P., García, C., Godoy, J.A. \& García-Castaño, J.L. (2007) Differential contribution of frugivores to complex seed dispersal patterns. Proceedings of the National Academy of Sciences of USA, 104, 3278-3282.

Keitt, T.H., Bjørnstad, O.N., Dixon, P.M. \& Citron-Pousty, S. (2002) Accounting for spatial pattern when modeling organism-environment interactions. Ecography, 25, 616-625.

Legendre, P. \& Legendre, L. (1998) Numerical Ecology, 2nd edn. Elsevier, Amsterdam, The Netherlands.

Levin, S.A., Muller-Landau, H.C., Nathan, R. \& Chave, J. (2003) The ecology and evolution of seed dispersal: a theoretical perspective. Annual Review of Ecology Evolution and Systematics, 34, 575-604.

Morales, J.M. \& Carlo, T.A. (2006) The effects of plant distribution and frugivore density on the scale and shape of dispersal kernels. Ecology, 87, 14891496.

Nathan, R. \& Muller-Landau, H. (2000) Spatial patterns of seed dispersal, their determinants and consequences for recruitment. Trends in Ecology and Evolution, 15, 278-285.

Petit, R.J., El Mousadik, A. \& Pons, O. (1998) Identifying populations for conservation on the basis of genetic markers. Conservation Biology, 12, 844-855.

Postma, E. \& van Noordwijk, A.J. (2005) Gene flow maintains a large genetic difference in clutch size at a small spatial scale. Nature, 433, 65-68.

Queller, D.C. \& Goodnight, K.F. (1989) Estimating relatedness using genetic markers. Evolution, 43, 258-275.

R Development Core Team (2009) R: A Language and Environment for Statistical Computing. R Foundation for Statistical Computing, Vienna, Austria. http://www.r-project.org.

Ritland, K. (1989) Correlated matings in the partial selfer Mimulus guttatus. Evolution, 43, 848-859.

Russo, S.E. \& Augspurger, C.K. (2004) Aggregated seed dispersal by spider monkeys limits recruitment to clumped patterns in Virola calophylla. Ecology Letters, 7, 1058-1097.

Schupp, E.W., Milleron, T. \& Russo, S.E. (2002) Dissemination limitation and the origin and maintenance of species-rich tropical forest. Seed Dispersal and Frugivory (eds D.J. Levey, W.R. Silva \& M. Galetti), pp. 19-23. CAB International, Wallingford, UK. 
Selkoe, K.A. \& Toonen, R. (2006) Microsatellites for ecologist: a practical guide to using and evaluationg microatellites markers. Ecology Letters, $\mathbf{9}$, 616-629.

Smouse, P.E., Long, J.C. \& Sokal, R.R. (1986) Multiple-regression and correlation extensions of the Mantel test of matrix correspondence. Systematic Zoology, 35, 627-632.

Smouse, P.E. \& Robledo-Arnuncio, J.J. (2005) Measuring the genetic structure of the pollen pool as the probability of paternal identity. Heredity, 94, 640-649.

Torimaru, T., Tani, N., Tsumura, Y., Nishimura, N. \& Tomaru, N. (2007) Effects of kin-structured seed dispersal on the clonal dioecious shrub Ilex leucoclada. Evolution, 61, 1289-1300.

Valière, N. (2002) GIMLET: a computer program for analysing genetic individual identification data. Molecular Ecology Notes, 2, 377-379.

Wenny, D.G. \& Levey, D.J. (1998) Directed seed dispersal by bellbirds in a tropical cloud forest. Proceedings of the National Academy of Sciences of the USA, 95, 6204-6207.

Ziegenhagen, B., Liepelt, S., Kuhlenkamp, V. \& Fladung, M. (2003) Molecular identification of individual oak and fir trees from maternal tissues of their fruits and seeds. Trees, Structure and Function, 17, 345-350.

Received 30 August 2008; accepted 21 August 2009

Handling Editor: Peter Klinkhamer

\section{Supporting Information}

Additional Supporting Information may be found in the online version of this article:

Figure S1. Map of the study area (c. 25 ha) showing the location of the sampling points (two seed traps per sampling station) according to microhabitat type.

As a service to our authors and readers, this journal provides supporting information supplied by the authors. Such materials may be reorganized for online delivery, but are not copy-edited or typeset. Technical support issues arising from supporting information (other than missing files) should be addressed to the authors. 
Abstract | References | Full Text: HTML, PDF (Size: 439K) | Supporting Information | Related Articles | Citation Tracking

Figure S1. Map of the study area (c. 25 ha) showing the location of the sampling points (two seed traps per sampling station) according to microhabitat type.

As a service to our authors and readers, this journal provides supporting information supplied by the authors. Such materials may be re-organized for online delivery, but are not copy-edited or typeset. Technical support issues arising from supporting information (other than missing files) should be addressed to the authors.

sm001.pdf (486k) (Adobe PDF) 


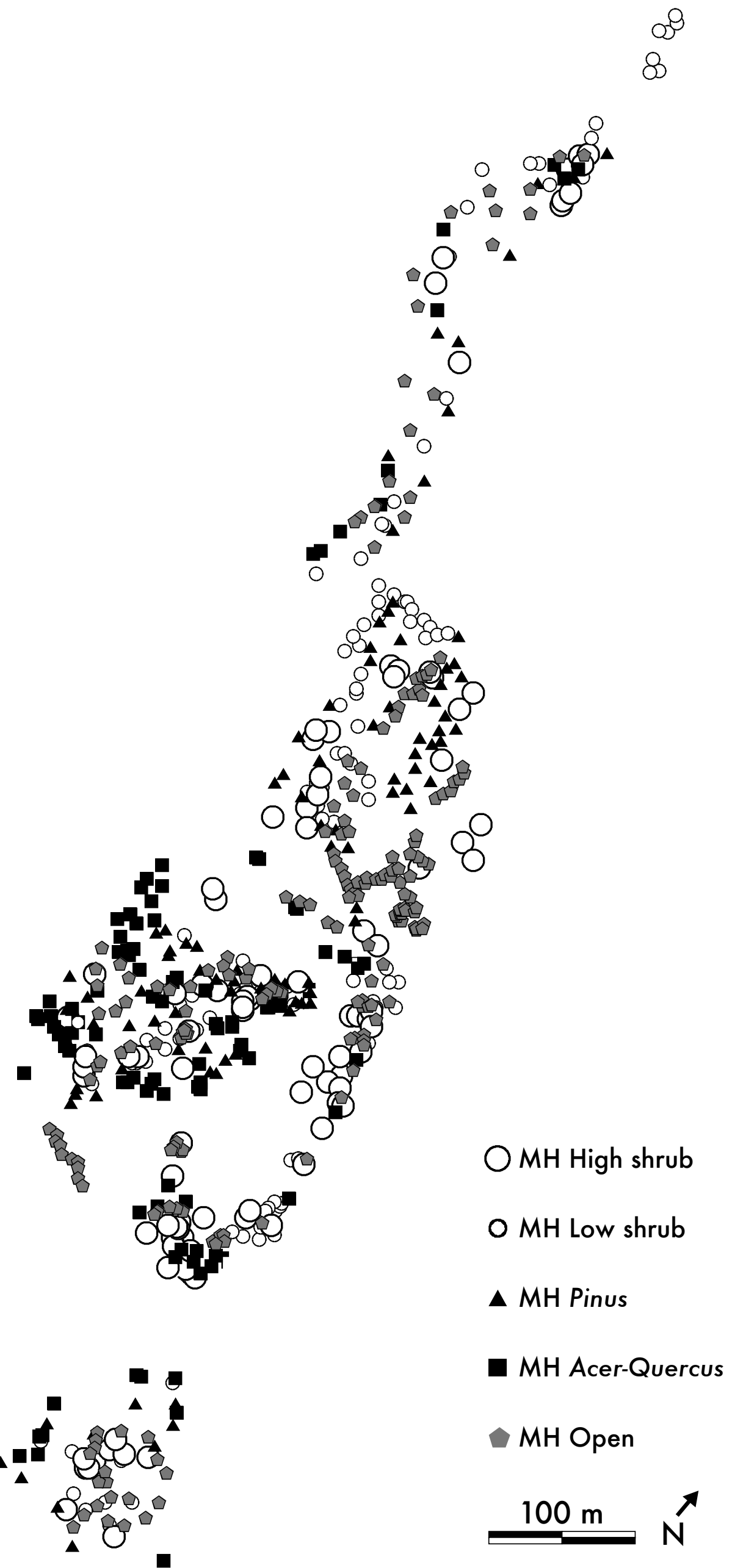

